\title{
¿Por qué el derecho positivo está en crisis?
}

\section{Why is positive law in crisis?}

Fecha de recepción: 20 de septiembre de 2011 Fecha de evaluación: 26 de septiembre de 2011

Fecha de aprobación: 10 de octubre de 2011

\author{
Eduardo Rodríguez M.*
}

\section{RESUMEN}

Este artículo reflexiona sobre los determinantes que vienen incidiendo sobre la crisis del derecho positivo propio o más asociado al modelo del Estado benefactor, con particular énfasis en el caso colombiano. En este sentido, el artículo desarrolla tres ideas básicas al respecto, a saber: en primer lugar, sugiere que durante el siglo XX el ordenamiento jurídico es de naturaleza positivista y kelseniana; en segundo lugar, que el ordenamiento jurídico es altamente concentrado, centralizado y jerarquizado; en tercer lugar, que este modelo a finales de siglo XX entra en crisis gracias a múltiples determinaciones debidas a las transformaciones de los procesos de trabajo y a la dinámica de los movimientos sociales. En conclusión, se advierte un proceso de descodificación, de pérdida de sistematización del ordenamiento jurídico y la aparición de nuevos ordenamientos jurídicos organizados bajo lógicas distintas a la codificación hegemónica precedente.

Palabras clave: sociología jurídica, positivismo legal, Estado benefactor, crisis del derecho, movimientos sociales, fordismo-taylorismo-keynesianismo.

Abogado, sociólogo, doctor en sociología jurídica e instituciones políticas de la Universidad Externado de Colombia. Profesor de la Facultad de Derecho de la Universidad la Gran Colombia y Profesor de la Universidad Nacional. E-mail: jrodriguezm2@hotmail.com 


\section{ABSTRACT}

This article reflects on the determinants that are having an impact on the crisis of positive law itself or associated with the model of the welfare State, with particular emphasis on the Colombian case. In this sense, the paper develops three points: First, it suggests that during the 20th century the legislation has positivist and kelsenian nature; Secondly, that the legal system is highly concentrated and centralized, and finally, that at the end of the 20th century, this model goes through a crisis because of many determinations due to changes in the work processes and the dynamics of social movements. In conclusion, we see a process of decoding, systematic loss of the legal system and the emergence of new legal logics organized under the preceding hegemonic code.

Keywords: Sociology of law, legal positivism, the welfare state, the law crisis, social movements, taylorismfordism-keynesianism.

\section{INTRODUCCIÓN}

Con la entrada en la denominada sociedad del conocimiento, propia del fenómeno de la globalización o mundialización, la literatura académica se viene preguntando sobre las tendencias del nuevo derecho global. Generalmente se trata de reconstruir las tendencias de la globalización del derecho como un problema estrictamente relacionado con las fuentes de producción del fenómeno de lo jurídico. Las tesis más difundidas señalan que la sociedad del siglo XXI advierte que el nuevo derecho se caracteriza por un proceso de construcción de un nuevo orden social que requiere, al mismo tiempo, producir un ordenamiento jurídico que lo acompañe. Ese nuevo derecho fundaría sus raíces no solo en los espacios nacionales, sino, principalmente, en los espacios internacionales. Hasta tal punto se ha venido a afirmar que sería necesaria una institucionalidad, incluso ya emergente, de naturaleza mundial o cosmopolita, en donde el Estado nacional sería tan solo una parte constitutiva de esa construcción. Estaríamos en el momento de advertir el nacimiento de una estatalidad y un ordenamiento jurídico estructurado por una sociedad red de Estados nacionales.

A pesar de ello, estas consideraciones no han examinado de manera rigurosa el estado de crisis en el que ha quedado el modelo del positivismo jurídico propio del Estado benefactor, comúnmente conocido en la literatura como monismo jurídico. Hoy es posible advertir, y ese es uno de los propósitos de este artículo, que ese modelo viene presentando graves fisuras y deficiencias, de modo que se puede señalar que ese tipo de ordenamiento y modelo jurídico no solo está en crisis, sino que, a su vez, bajo las condiciones generadas por la nueva estructura y organización de la producción no corresponde al modelo que la sociedad contemporánea está requiriendo.

Los trabajos de la globalización del derecho no advierten que el modelo positivista kelseniano del pasado ya no es ni suficiente ni contiene la lógica inherente de las nuevas relaciones productivas. A pesar de ello, cuando se analizan las tendencias de la globalización del derecho, se parte de la hipótesis de que en el mundo de la globalización el ordenamiento jurídico cambia solamente de escala, sin reconocer que el problema contemporáneo no solo puede ser visto como un problema asociado a la escala, sino que también, así lo advertimos, las tendencias de globalización del derecho deben producir nuevas referencias y construcciones, en la medida en que el nuevo derecho no puede basarse en la prolongación y extensión de la lógica del monismo jurídico. 
Es por ello que en este artículo queremos presentar algunas aproximaciones que pretenden dar cuenta de las fuerzas que han venido generando la crisis del positivismo jurídico, en su forma de monismo legal, para dar elementos de análisis posteriores sobre la imposibilidad social e histórica de la continuidad de esta forma de ordenamiento legal y, asimismo, sobre la urgencia de implementar nuevas estructuras jurídicas más próximas al nuevo orden social y político en construcción.

\section{PROBLEMA DE INVESTIGACIÓN}

El presente artículo pretende resolver dos problemas básicos de investigación, a saber: de un lado, comprender por qué razones entró el modelo del positivismo jurídico en crisis y, de otro lado, si la crisis del ordenamiento jurídico está relacionada con determinantes pertenecientes a su propia lógica de funcionamiento o a causas más próximas a los procesos de trabajo y a los movimientos sociales.

\section{METODOLOGíA}

Si es que podemos aproximarnos a una descripción de una metodología para la elaboración de este artículo, podríamos sintetizarla diciendo que se trata de un trabajo analítico deductivo, teórico-crítico y basado, en algunos aspectos, en la observación propia del trabajo de campo y en la práctica teórica. En este sentido, se realizó un trabajo de análisis de textos, dentro de un ejercicio comprensivo de los posibles impactos de las tendencias contemporáneas de renovación del derecho, sobre fuentes basadas más en los aportes del conocimiento científico y técnico, que en la racionalidad inherente o propia de los sistemas legales.

\section{CONTENIDO}

\section{A. Aproximación histórica y conceptual}

Podemos hallar los orígenes del Estado de bienestar en Colombia en el declive de la hegemonía conservadora y en el desarrollo del proceso modernizador y de industrialización, periodo que coincide a nivel mundial con el agotamiento del capitalismo liberal de libre competencia, en los términos en que nos lo ha presentado Karl Polanyi (1997). No es nuestro interés entrar a describir las formas y devenires del proceso de industrialización en el país durante ese periodo, pues a nuestro juicio existe una abundante bibliografía de historia económica que nos permite comprender sus características y ciclos más importantes. Para nosotros resulta de mayor importancia sugerir algunas tendencias generales que caracterizaron esta fase de la organización social productiva que denominamos "taylorista-fordista-keynesiana" y que, al igual que en otras latitudes, se agotó en la década de los ochenta del siglo XX. Para examinar el mundo del derecho, la justicia y el Estado es necesario apelar al estudio de la economía y de las formas de propiedad, con el fin de construir un camino que nos permita entender los cambios operados en las relaciones sociales en el conjunto de la formación social colombiana. Hay que señalar (lo que supone ya un lugar común) la ausencia de trabajos e investigaciones en el país sobre la historia del derecho y sus instituciones, hecho que dificulta nuestra tarea; además, dadas las limitaciones inherentes a nuestra propia investigación, nos vemos obligados a sugerir algunas tendencias generales que podrán ser o no corroboradas por estudios más particulares o puntuales.

Quisiéramos señalar, para comenzar, algunas características básicas del ordenamiento social, jurídico y político que provocó el cambio paulatino de las relaciones sociales productivas, el cual, a su vez, terminó por perfilar una nueva fase de acumulación y valorización capitalista. Algunos de los elementos más destacados podríamos presentarlos de la siguiente manera:

1. La crisis de la bolsa de Nueva York, en 1929, no tuvo un impacto negativo en términos capitalistas para países como Colombia, en la medida en que la nuestra era una economía de porte medio, es decir, con baja capacidad 
exportadora, un débil mercado interno basado sobre economías locales o regionales, con niveles de incorporación tecnológica muy reducidos, con un esqueleto productivo casi inexistente y, por último, en donde el mayor peso o forma de producción de la riqueza social era de base rural.

El periodo liberal en Colombia comenzó con esta estructura productiva y demográfica básica. El antiguo régimen se sustentaba en el predominio de la propiedad privada como valor absoluto del Estado gendarme -cuya función era la de proteger el denominado orden público-barrera-, y de los derechos civiles y políticos fuertemente atados al nivel de ingresos de las personas y sus derechos patrimoniales; en él predominaban también la llamada ciudadanía plebiscitaria y una economía pública débil y precaria que se alimentaba fundamentalmente del impuesto de aduanas y de impuestos indirectos que pretendían proteger la formación del gran capital, su concentración y su centralización.

Incluso la inversión extranjera directa (IED) siempre se caracterizó por ser de naturaleza extractiva, sin generar recursos para la inversión endógena. En otras palabras, frente al mercado mundial, el antiguo régimen estaba basado en la producción de la gran hacienda que, combinada con la economía parcelaria, articulaba formas precarias de acumulación no intensivas, sino de naturaleza extensiva, impidiendo la formación acelerada de capital fijo dentro del territorio nacional y animando tan solo el consumo suntuario de las clases pudientes que residían o se desplazaban en o por fuera del territorio del Estado-Nación. Por tales motivos, la crisis del capitalismo internacional desencadenada a partir de la quiebra de la bolsa de Nueva York de 1929 no nos impactó, sino que sirvió para que el capital internacional encontrara en países de la periferia como Colombia un espacio para resolver su contradictorio desarrollo interno, apelando a una política expansiva mediante la IED y la construcción del territorio más propicio para que la nueva fase de acumulación a nivel internacional cimentara los elementos necesarios para echar raíces.

Colombia, y en general América Latina, fueron la salida a la temprana crisis de la industrialización del centro, generada ya por el fordismo que se impulsaba con fuerza desde comienzos del siglo XX, con el famoso Ford T, especialmente en Estados Unidos. A su turno, el país intentaba superar sus límites con el desarrollo sin precedentes del sector bancario en su forma de capital financiero, el impulso de la sociedad por acciones, el despertar y fortalecimiento de las instituciones y de los instrumentos crediticios que el nuevo modelo de valorización exigía, etc. En esta medida, para Colombia la industrialización requirió un proceso de "maduración" con grandes sobresaltos, con desestructuración de la economía campesina y de las relaciones productivas de bases agrarias; proceso caracterizado por el desarrollo del fenómeno de la violencia política y la construcción, simbólica o no, de un Estado "benefactor", "protector" o "regulador", pero que, de cualquier forma, se comportaba como Estado intervencionista en la mayor extensión del concepto.

2. Al contrario de lo señalado por Weber, el principio racional que primó en Colombia hasta finales del mismo periodo del bienestar no fue la ética protestante, sino una subordinación de la misma dominación legal racional del derecho y la burocracia al orden y al culto religioso católico. Desde el antiguo régimen, el Estado liberal de la Constitución de Rafael Núñez cedió gran parte de la soberanía nacional al entregarle la formación del concepto de "pueblo" a la Iglesia Católica mediante la celebración del Concordato realizado entre Colombia y la Santa Sede. El monismo jurídico al que nos referimos más arriba no se dio en 
sentido riguroso en nuestro país, en la medida en que siempre coexistieron ordenamientos legales y jurisdicciones especiales para ciertos grupos de la sociedad.

3. A pesar de ello, para poder ser efectiva, la modernización del país requirió de una reforma constitucional -realizada por Alfonso López Pumarejo en 1936- que, inspirada en las tesis modernas de León Duguit, consagró entre los más fundamentales cambios el principio constitucional de la función social de la propiedad. Este principio o norma constitucional puso las bases del intervencionismo del Estado para ese periodo y de la construcción paulatina del Estado de bienestar.

4. El primer efecto de esta innovación constitucional fue la promulgación de la Ley 100 de 1938 o Ley de reforma agraria, la conformación de las primeras centrales de trabajadores (UTC y CTC, entre otras), la reglamentación de la figura de la expropiación -pero por sentencia judicial-, la elaboración y expedición de los códigos procedimental y sustantivo del trabajo, etc. A pesar de lo anterior, el advenimiento de la Segunda Guerra Mundial y la difícil década de 1940, con todo ese escenario de barbarie, arrastró al país a transformar su mapa demográfico durante la siguiente década, para girar el eje sobre el que descansaba la producción de la riqueza social. El fenómeno de la urbanización, especialmente de la ciudad "espontánea" y, sobre ella, el montaje incompleto del esqueleto productivo de la industrialización; la aparición del desarrollo regional desigual, la emergencia de una reorganización de las finanzas públicas sustentadas sobre los impuestos directos de renta y patrimonio; la dinámica y fortalecimiento de una economía pública con pretensiones de autonomía relativa frente a la economía privada y el avance inusitado del derecho público en su forma de derecho administrativo fueron transformaciones que se pretendieron racionalizar $y$ establecer en la reforma constitucional de 1968 , bajo el gobierno de Carlos Lleras Restrepo.

5. El capitalismo del Estado benefactor transformó radicalmente la dinámica de su antecesor. Dentro de este periodo que, como hemos insistido, comienza en los años treinta y se agota a finales de la década de los setenta, se produjeron cambios muy importantes en la dinámica del capitalismo que motivaron un replanteamiento de los fines del Estado y de la concepción de la ciudadanía. Entre las transformaciones sufridas podemos señalar las siguientes:

- Se dio predominio a la familia nuclear consanguínea y a la participación de la mujer dentro del mercado laboral.

- La esfera del consumo fue absorbida por la esfera de la producción, provocando una desnaturalización de la esfera de la reproducción asumida por la familia.

- El Estado empezó a intervenir no solo en la economía, sino, de igual manera, en el conjunto de la vida social. Lo público se introdujo en la órbita de la vida privada, despojándola de su propia racionalidad. En otras palabras, la racionalidad instrumental, característica de la esfera de lo público, transformó el mundo de la racionalidad comunicativa prevaleciente en la vida privada.

- Se organizó el mercado laboral y se dio predominio a la sociedad estructurada en clases sociales.

- Nació y se consolidó el concepto de la responsabilidad social, en la medida en que la producción promovía un movimiento enorme de socialización de las fuerzas productivas. La urbanización fue el producto de esa socialización del individuo, dando lugar a la aparición del individuo social, categoría muy distinta a la del individuo posesivo del periodo anterior. 
El capitalismo liberal dio prioridad al desarrollo del concepto de libertad en detrimento de la igualdad social. En el capitalismo del Estado benefactor se pretendía responder al déficit de igualdad no cumplido por esa fase. En ese sentido, el concepto de ciudadanía se extendió y transformó. De un lado, asistimos a un proceso de universalización de la ciudadanía y de otro, la ciudadanía dejó de expresar tan solo un concepto político para asociarse a los derechos económicos y sociales. Fue así como nació el concepto de los derechos humanos de segunda generación.

La sociedad del Estado benefactor se caracterizó por el consumo masivo que los alcances y logros de la producción en serie o fordismo hicieron posible. Con ello, la ciudadanía no solo se definió con base en la participación en la vida del Estado, sino también en la participación del producto socialmente producido. Así, la ciudadanía se convirtió en la capacidad de los individuos de ser consumidores $y$, a través de esa nueva función, ejercer su poder social de orientar a la colectividad a través de la producción y satisfacción de las necesidades. Apareció entonces el ciudadano consumidor.

Como podemos observar, durante este periodo se consolidó la articulación entre política y economía, al variar radicalmente la actividad estatal como reguladora del mercado. El Estado pasó a dirigir la economía para garantizar los periodos de estabilización económica. Esta fase fue especialmente favorable para que el Estado interviniera, mediante una política pública centralista, en la provisión de las condiciones generales necesarias para la reproducción del capital constante y del capital variable. Con este esfuerzo, el Estado logró diseñar un aparato productivo de naturaleza nacional, rompiendo las barreras del mercado fragmentado del periodo anterior. Mediante la asociación del capital público, el capital privado nacional y el capital internacional, y a través de la figura de las joint ventures, buscó impulsar la acumulación capitalista y evitar las crisis periódicas del capital, mientras intentaba contrarrestar la caída tendencial de la tasa de ganancia a través de la desvalorización de una masa de capital como capital público. Las políticas públicas y el gasto social aparecieron como una contra-tendencia de la crisis de realización de la mercancía.

En este sentido, para resumir, podemos decir que las políticas públicas y el gasto público tenían que responder de manera global a los siguientes requerimientos del proceso de acumulación, a saber:

a) Contrarrestar la crisis de la acumulación ocasionada por la baja tendencial de la tasa de ganancia, mediante la creación de una masa de capital público que se presentaba como capital desvalorizado en la medida en que no reclamaba una tasa de ganancia. Esa es su gran diferencia con el capital privado.

b) Abaratar los costos de producción del capital constante mediante su participación directa en la elaboración y producción de bienes y servicios industriales $y$ de aquellos propiamente considerados como participantes de las condiciones generales de la producción, como las comunicaciones, la urbanización, los servicios públicos, las obras de infraestructura, etc.

c) Abaratar los costos de producción del capital variable o costos de reproducción de la fuerza de trabajo a través del denominado salario indirecto. En ese sentido, tenemos la atención preferencial a la familia, a los ancianos, a los pobres, etc.

d) Impulsar la ampliación del mercado nacional mediante la universalización y homogenización de las relaciones sociales de producción, de suerte que pueda existir una libre movilidad del capital y de la fuerza de trabajo. Asimismo, contribuir con el desarrollo del proceso de asalaramiento para garantizar la provisión de suficiente fuerza de trabajo disponible para las necesidades de la acumulación y la suficiente 
competencia entre los asalariados para regular el precio de la mano de obra.

Durante este periodo, la legitimación del régimen político estaba soportada por la pareja eficienciaredistribución. La separación entre Estado y mercado era casi inexistente, y en tanto que el Estado actuaba como agente económico, el éxito de su labor estaba determinado por la eficiencia de su actividad productiva. Esta eficiencia abarcaba no solo los aspectos del capital público desvalorizado encaminado a impulsar ciertos aspectos de la actividad económica, sino, también, su capacidad de lograr mantener el equilibrio macroeconómico y la expansión permanente del capital mediante el intervencionismo económico. De otro lado, así como una de las funciones sociales del Estado interventor era la de servir de garante ante las contingencias que sufrieran los desvalidos por causa de la competencia y la inasistencia social, su otra función radicaba en apoyar, mediante su intervención pública, a los grupos sociales que se encontraban en posición de indefensión a través de una política redistributiva que compensara los efectos nocivos de la excesiva concentración y competencia capitalista. Es el caso de los desocupados, las mujeres, los niños, ancianos, los pobres, etc.

Por el grado de extensión del mercado y la homogenización del espacio de la acumulación, las políticas públicas adquirieron una naturaleza general y universal. Estuvieron encaminadas a satisfacer las necesidades de la población en su conjunto sin olvidar su carácter redistributivo. En este sentido, la universalización de las políticas públicas se dio de modo paralelo y en correspondencia con la universalización del mercado y la existencia de una ciudadanía amplia y general. Dentro de este periodo, la ideología del ciudadano se hizo ampliamente extensiva y, por ende, constituyó la base para una amplia tributación. Los recursos del Estado se agruparon de modo importante en el nivel central, el cual redistribuía los recursos de acuerdo al balance de fuerzas sociales y regionales.

Este fue el periodo de la centralización y jerarquización del Estado que, amparado en la figura de la democracia representativa, se encargaba de las funciones sociales sin ningún tipo de participación comunitaria. Se trataba, pues, de un régimen centralista altamente excluyente en cuanto a las decisiones y en el que los ciudadanos participaban solamente a través del sufragio.

Es necesario hacer algunas precisiones en relación con las transformaciones que sufrió la organización social durante esta nueva fase, pues estas implicaron un replanteamiento más o menos significativo de las relaciones entre Estado y economía, así como de la articulación entre las diversas instancias (política, economía y cultura) requeridas o demandadas por las nuevas dimámicas sociales de producción y los dilemas que suscitaban los nuevos movimientos sociales, a saber:

a. El proceso de trabajo basado en la organización taylorista y fordista modificó el esqueleto productivo de la fase anterior, y ello no solo desde la dimensión de la firma tradicional, sino también desde aquella de la estructura interempresarial, en la medida en que al ampliarse el espacio de producción y circulación de mercancías, este tipo de firma podía replantear los criterios de localización que antes estaban orientados hacia los lugares de localización de las materias primas y ahora empezaban a privilegiar la localización de los mercados y los consumidores. En los países de la periferia, como Colombia, la firma tendía a abastecer todo el territorio nacional y a reorganizar la producción hacia el comercio exterior. La firma de este periodo impuso una readecuación de las condiciones generales de la producción, tal como sucedió con la infraestructura vial, de comunicaciones y de organización del tejido urbano que reclamaba a su vez saneamiento 
básico y vivienda, así como la expansión del medio urbano construido.

b. En razón del tamaño de la firma, se intentó generar un proceso de construcción de un esqueleto productivo completo (bienes de producción, intermedios y de consumo) que posibilitara la adecuación de un mercado interno relativamente autónomo, el cual, a su turno, permitiera un proceso de acumulación endógeno. Como la naturaleza de la firma privilegiaba la producción en serie, se hizo necesario organizar el consumo masivo de la población con la pretensión de lograr un punto de equilibrio entre la oferta y demanda de mercancías. Así, la firma fordista y la sociedad de consumo constituían la expresión de una misma ecuación entre oferta y demanda.

c. Además, la naturaleza de la producción en serie obligó a organizar el consumo de manera empresarial. La economía doméstica sobre la cual se apoyaba la reproducción social tendió a diluirse, en el sentido en que parte del capital social se desplazó hacia esta región con un doble propósito: de un lado, disciplinar el consumo y permitir que la forma salarial se dirigiera a convalidar la producción industrial, reduciendo así los problemas surgidos por una posible crisis de desmercantilización del producto social; $y$ de otro lado, permitir un espacio adicional y bastante significativo para la valorización capitalista, en la medida en que se potenciaba enormemente el sector de los servicios que cumplían todos los requerimientos para desarrollar la reproducción. La reproducción social no solo se restringió a la creación de bienes y servicios materiales, sino que comprometió, además, la reproducción generacional de los productores en la educación, la cultura y las políticas de integración social que en su conjunto se encaminaron a lograr la reproducción intergeneracional de la fuerza de trabajo. d. Esta producción industrial de las formas de vida fue facilitada por la integración de la mujer al mercado laboral, quien abandonó parcialmente la función que históricamente le había otorgado la división sexual del trabajo. Bajo estas condiciones se generó un proceso de mercantilización y asalariamiento de la reproducción social, relativizando de suyo el papel de la familia (ahora nuclear y ya no extensa) en atención de la reproducción biológica e intergeneracional de sus miembros.

e. La sociedad salarial sufrió una profunda mutación al desnaturalizarse el concepto del salario familiar. Con la individualización y asalariamiento de la mujer en el mercado laboral el salario se desdobló, gracias a la participación del Estado en el salario directo e indirecto. El directo, correspondiente al pago o remuneración por el esfuerzo del trabajo dentro de la actividad productiva, adquirió una significación distinta a la que tenía en el periodo anterior, al pasar de ser familiar a ser relativamente individual. El salario indirecto era atendido por el Estado, que encontró en la tributación un mecanismo importante para su provisión. El gasto público se constituyó como una segunda vía del salario que permitía atender parcialmente la cuota de los bienes que el salario directo no lograba cubrir. Esta transformación de la sociedad salarial estuvo ligada de modo estructural a las necesidades de la sociedad de consumo y de la producción en serie. Con ella se pretendía paliar la crisis de realización de las mercancías y permitir que el ciclo industrial tendiera a crecer incesantemente.

f. En la esfera política, los derechos civiles y políticos se hicieron extensivos a toda la comunidad, de suerte que se pudo estructurar de manera sólida y coherente el sistema de representación a través del sistema político de partidos. Al igual que el mercado de bienes y servicios tuvo que ampliarse para poder dinamizar el 
intercambio de mercancías, fue necesario ampliar y generalizar el mercado político para permitir la gobernabilidad de la fase mediante la obtención y producción de consensos ciudadanos que le dieran al Estado la legitimidad necesaria para impulsar los requerimientos de la sociedad salarial, especialmente en lo referente al direccionamiento del gasto público y la cohesión social que demandaba el nuevo modelo de acumulación. De igual manera, se abrieron camino los denominados derechos económicos y sociales o derechos de segunda generación, a través de los cuales se reconoció a la ciudadanía el acceso a los bienes socialmente producidos dentro de las nuevas condiciones de la intervención del Estado. En ese contexto, la nueva relación que surgió entre el Estado y la sociedad puede ser entendida como un proceso de ampliación de la ciudadanía desde una perspectiva económica. La nueva ciudadanía implicaba que los actores de la sociedad civil adquirieran derechos frente al Estado, en el sentido en que podían demandar de este la provisión de bienes y servicios como parte del nuevo pacto social.

g. Como ya lo hemos advertido, en este periodo nació la figura del ciudadano consumidor, que es definitiva en el nuevo papel del Estado dentro del mercado y de una ciudadanía más próxima al desarrollo del principio de igualdad que al principio de la libertad tal como se desarrolló en el periodo anterior. Sin embargo, la nueva concepción de ciudadanía se encontraba vinculada a la dinámica y posibilidades de la economía como un todo $y$, especialmente, al tamaño y dinamismo del Estado. En países como Colombia, y en general en la periferia, el nuevo ciudadano consumidor se constituyó en un principio restringido, debido a los problemas estructurales impuestos por el subdesarrollo. De esta forma, las limitaciones del crecimiento económico dieron lugar a nuevos campos del conflicto social en donde necesariamente se confundió la función del Estado político del capitalismo liberal con la naturaleza del Estado empresario del capitalismo benefactor. Aquí economía y política se entrecruzaron y confundieron, de forma que tendió a desaparecer la autonomía relativa con que se diferencian estas dos instancias.

Durante esta fase se extendió el proceso de asalariamiento de la sociedad, condición que exigió la regulación de las relaciones laborales a través de la expedición de los códigos sustantivos y procedimentales del trabajo, encargados de construir las reglas del juego entre empresarios y trabajadores. De la misma forma se extendió y amplió el predominio del derecho público como derecho administrativo que permitía controlar y vigilar la función pública en todas las áreas en donde ella se desempeñaba, como también regular la relación cada vez más importante y significativa entre Estado y particulares.

Al adquirir la propiedad una función pública, el Estado empezó a intervenir ostensiblemente en la administración de los bienes públicos dentro de un medio urbanizado y estructurado de modo preponderante en torno al espacio público. La existencia de un espacio público extendido permitió crear nuevos mecanismos legitimadores de la acción colectiva bajo el principio del interés general. Lo público no se restringió a las denominadas condiciones generales de la producción (calles, parques, servicios públicos, etc.), sino que lentamente cobró mayor cobertura al extenderse a áreas que anteriormente estaban a cargo estrictamente de los particulares como la familia, la niñez o la autonomía de la voluntad privada -en lo concerniente, por ejemplo, a la salud y la educación-.

Con la invasión del Estado en el mundo de la vida, como lo señala Habermas, los principios legitimadores de la sociedad tendieron a ser sustituidos por principios propios de la racionalidad de la ciencia y la técnica, o racionalidad instrumental, 
amparados por la economía de la eficiencia y eficacia, relegando así formas de legitimación como el parentesco, la división sexual del trabajo y la acción comunicativa, entre otros. El Estado se vio inmerso en las tensiones que surgieron entre la racionalidad instrumental de la sociedad industrial y la necesidad de reconocer espacios de racionalidades alternativas o tradicionales, mostrando en muchos casos ciertas tendencias autoritarias por su afán de homogenizar y universalizar la producción de las formas de vida. Se dio lugar así a la estandarización y predominio del pensamiento único sobre todas las áreas de la producción de la existencia social, bajo las directrices del pensamiento técnico-científico de carácter positivista imperante en las ciencias naturales, que al extenderse comenzó a gobernar también en las ciencias sociales y en la política.

Durante este periodo la ciudadanía social cobró mayor relevancia, especialmente en lo referente a los derechos ciudadanos garantizados por el Estado benefactor. Los movimientos sociales tradicionales, sin embargo, no incorporaron la ciudadanía de la primera generación, sino que intentaron expresarla por fuera de sus organizaciones naturales. En la medida en que se mantenía aún una separación entre los asuntos económicos y políticos, la ciudadanía en cuanto tema público fue asumida como una tarea de las organizaciones clásicas de los partidos políticos. En cambio, los denominados nuevos movimientos sociales, que se expresaron básicamente en el área de la reproducción social, integraron la ciudadanía social como parte fundamental de su acción.

En efecto, en los países de la periferia capitalista el déficit fiscal fue una de las situaciones que motivaron el derrumbe del Estado benefactor. Esta situación estructural trajo consigo limitaciones substantivas que impidieron al Estado extender el modelo del bienestar a toda la población y esta fue, justamente, una de las razones para que los nuevos movimientos sociales asumieran las bande- ras de la ciudadanía social como causa básica de su lucha dentro del proceso de democratización de la sociedad. Si bien es cierto que en el centro capitalista la ciudadanía social se expresó a través de la figura del ciudadano consumidor que no solo intentaba ejercer, desde la demanda, sus derechos al consumo de bienes y servicios, sino que también pretendía influir en la esfera de la producción - como sucedía con los movimientos ecologistas y ambientalistas-, tambien es verdad que en la periferia los nuevos movimientos sociales organizaron sus demandas alrededor del Estado de bienestar como garante y proveedor de los derechos ciudadanos. Esta situación terminó por centralizar los conflictos sociales, ocasionando una nueva crisis que en muchas partes ha sido caracterizada como "de legitimación". La ciudadanía social desnaturalizó y tensionó la relación existente entre el Estado y la sociedad, produciendo en muchos casos la desestructuración del proceso de formalización o racionalización social -por ejemplo, a través del derecho- requeridas por la modernidad, dando inicio a un proceso de desintegración social y de resquebrajamiento de los mecanismos de construcción de las síntesis sociales. Ese proceso se profundizó hasta el punto de llegar a percibirse la existencia de nodos o circuitos sociales de baja integración sistémica -es decir, aquella que abre las posibilidades del desarrollo y coexistencia de sociedades relativamente paralelas-, desdibujando el concepto global de sociedad como un todo integrado y coherente.

En relación con el derecho legal formal, para la década de 1970 la estructura burocrática de la administración de justicia presentaba algunas características que la alejaban de poder reaccionar a los dilemas del mundo y a la dinámica del derecho racional material, que podríamos sintetizar como sigue:

a) La división tripartita de poderes tenía una estructura débil y precaria. Los excesos del presidencialismo durante el denominado Frente 
Nacional y la famosa legislación del Estado de sitio y la emergencia económica generaron durante un periodo significativo una "suspensión" de la normalidad jurídica, cuyo efecto inmediato fue una especie de subordinación de la rama jurisdiccional a las necesidades que brotaban o se justificaban por el orden público. Pero también puede aducirse que esta rama no gozó del reconocimiento suficiente por parte del Estado como para ver satisfechas las condiciones que, en materia presupuestal y en el número de funcionarios adscritos a ella, hicieran posible su funcionamiento. La administración de justicia era tenida como la cenicienta de las ramas del poder público. En términos de Bourdieu (2001), ella no gozaba de capital social, cultural o simbólico en comparación con los otros órganos de poder del Estado.

b) De lo anterior puede deducirse que la administración de justicia estaba sujeta a las presiones ejercidas por una parte de la sociedad, hacendaria y de estructura gamonalista, en la que luego se desarrollaron relaciones clientelistas - de carácter más urbano- que la utilizaba como el lugar privilegiado, por estar bajo su control y potestad para sacar adelante y sin mayores dificultades resoluciones que fueran favorables a sus intereses. Por ello, la administración de justicia no gozaba de credibilidad entre los grupos sociales que no tenían una posición dominante en la sociedad, los cuales, por el contrario, buscaban huir del terreno que ella les ofrecía para la resolución de sus conflictos, fueran estos de naturaleza individual o colectiva. En el imaginario de los actores no dominantes dentro de las relaciones socio-jurídicas, la justicia era vista como "un perro bravo que solo muerde a los de ruana".

c) De igual manera, los excesos del formalismo legal, la racionalidad de sus procedimientos, la demora en obtener decisiones relativamente rápidas y confiables, la inseguridad que en mu- chos casos ocasionaba colocar los intereses en disputa en cabeza de un "abogado tradicional" -de quien poco sabían y que muchas veces pertenecía a grupos familiares y profesionales que no permitían construir identidad social-, entre otros factores, provocaron que la población se hiciera renuente a acudir a la justicia y su derecho. En esta época nació la que nosotros podemos llamar "teoría del acceso" que, apoyándose en esa dinámica e imaginarios de la población, sostenía que la crisis de la justicia en Colombia se debía a un problema de canalización de los conflictos sociales por el laberinto de los abogados, los jueces y los tribunales. Ante este panorama, la sociedad colombiana resolvía sus controversias apelando a formas novedosas o particulares, acordes a sus tradiciones culturales, religiosas o político-sociales, generando, entre muchos otros efectos, un fenómeno de pérdida de autoridad de la ley y del Estado. Incluso los derechos que pretendió consagrar el periodo de bienestar, basados sobre los principios de libertad e igualdad ante el mercado y el Estado, no encontraron cabida en esta dinámica de los actores y movimientos sociales.

d) En una perspectiva similar, se pensaba que el acceso a la administración de justicia estaba íntimamente asociado a factores de índole económica: los altos costos del litigio, la mediación del abogado que fijaba sus honorarios de conformidad con el papel que cumplían sus asociaciones y corporaciones, las cuales defendían el ejercicio liberal de la profesión, entre otros, constituían obstáculos insalvables para apelar a la administración de justicia. Como resultado de los análisis que daban cuenta de esa situación, se comenzó a regular el ejercicio de las asociaciones de abogados y a limitar el valor de sus servicios, a organizar los llamados consultorios jurídicos de las universidades -que en teoría prestarían una oferta legal gratuita para determinadas causas y bajo la tutoría de los maestros- e igualmente se 
impulsó la figura de los defensores de oficio, en materia penal, para aquellas personas que pudieran demostrar su indigencia para cubrir los costos del proceso. Por último, ya para este periodo comenzó a florecer, gracias a la ayuda institucional, nacional o internacional, una oferta relativamente pequeña para impulsar los servicios legales destinados a los grupos sociales no dominantes, con el fin de superar lentamente los problemas sociales y políticos que conllevaba el deficiente acceso a la justicia.

e) Como dato curioso podemos citar el trabajo del profesor Rogelio Pérez Perdomo (2004), quien nos presenta una información muy sugerente. Para el periodo transcurrido entre 1970 y 1980 , en el que en apariencia el proyecto del Estado de bienestar comenzaba a consolidarse en nuestro medio, por ejemplo a través del impulso de la profesionalización de los oficios y de la cobertura universitaria, se observa cómo a pesar de que el ingreso promedio de los abogados tendía a disminuir, se presentaba simultáneamente una tendencia al incremento de los estudios en las carreras de derecho, tanto para hombres como para mujeres. Fue una época durante la cual se fue desvaneciendo la figura de las otrora asociaciones de abogados que protegían el llamado ejercicio liberal de la profesión, y se avanzó hacia una nueva condición que podría caracterizarse como una "proletarización" de los abogados.

Sin embargo, a pesar de que el Estado se constituiría en el gran empleador de los nuevos profesionales junto con las firmas multinacionales, se podía percibir cómo del seno de los actores no dominantes nacía un proceso de preparación dentro de la profesión de abogado. Sin duda alguna, algunos querrían continuar con la tendencia histórica señalada por Pérez Perdomo, especialmente para el siglo XIX, como hacedores de la política y formando parte en la constitución de las élites emergentes; pero para la gran mayoría, el ejercicio profesional de la abogacía significaría una herramienta -aunque de doble filo- para transformar esta etapa de la teoría del acceso y adentrarse en 1980 a un nuevo escenario social y político que a continuación describiremos brevemente.

Antes que todo es necesario advertir que la fase de la acumulación y valorización fordista comenzó a derrumbarse en los países centrales desde mediados de la década de 1970. Para ese entonces la política norteamericana de apoyo a las dictaduras y a los regímenes de excepción política y legal, especialmente en América Latina, perdió a su aliado estratégico. El presidente J. Carter impulsó a nivel mundial la defensa de los derechos humanos, la restauración de los derechos civiles y políticos y la defensa de los principios democráticos basados en la igualdad y la redistribución del ingreso. Para tales efectos, el Nuevo Orden Económico Internacional (NOEI), que parecía propiciarse y que se basaba en la libre autodeterminación de los pueblos, contó con una política de préstamos y de endeudamiento externo de los países de la región, con la perspectiva de continuar el proyecto inacabado del bienestar. A este preámbulo tan solo nos falta añadir que la década de los ochenta en América Latina ha sido denominada la década perdida, en el sentido en que no hubo crecimiento y los países de la región se dedicaron a pagar su deuda o a renegociarla.

Durante esa década, el movimiento social encaminó sus esfuerzos en varios sentidos: la democratización, el fortalecimiento del Estado desde la perspectiva del pacto del Estado de bienestar (Ios derechos económicos, sociales y culturales, DESC) y la normalidad democrática desde el punto de vista del ordenamiento jurídico y político. Podríamos decir que estas pocas características generaron un desbordamiento de los conflictos sociales, que entonces empezaron a operar bajo la lógica del derecho legal formal y a apelar, mediante la racionalización legal formal y no la legal material de la década anterior, a los derechos suspendidos 
durante décadas por los estados de excepción. Este fenómeno puede ser visto como una transformación en las modalidades de la "gobernabilidad" del régimen político frente a los avatares, dilemas y contradicciones de la fase de acumulación fordista.

Sin duda alguna, el cambio en las motivaciones y estrategias de los actores sociales suscitó una nueva forma de presentación de la crisis en los años ochenta: la crisis de la congestión judicial. Si en el pasado la justicia no tenía un papel protagónico, ahora sus funciones se veían fuertemente interpeladas: debía responder desde su precariedad a los retos del presente. Con la congestión judicial, la crisis de la justicia se convirtió simultáneamente en crisis del Estado constitucional de derecho'.

Quisiéramos señalar que curiosamente en la década de los ochenta, cuando el Estado de bienestar ya había colapsado, en el centro capitalista se había difundido una idea (malintencionada o no) de que el mundo se había encaminado a mantener una expansión ad infinitum del bienestar, sobre sus propias bases, postulados y ordenamiento social y político. A nuestro juicio, sin embargo, esa década fue el periodo de transición que permitió la readecuación de una nueva fase de la organización social productiva, en la que algunas latitudes del planeta requerían anticiparse a las demás para imponer su comando y, así, estar en mejores condiciones generales para afrontar los nuevos tiempos, mientras se generaba la famosa "decisión" conocida como el Consenso de Washington².

1 Vale la pena señalar que ya organismos como el Banco Mundial habían previsto el impacto negativo de la naciente crisis de la congestión judicial para la acumulación de la riqueza social. Desde entonces, se ha venido trabajando incesantemente en analizar este fenómeno con el fin de poner en marcha políticas tanto de choque y ajuste como de naturaleza "estructural" para mitigar los efectos de lo que los neo-institucionalistas han denominado los costos de transacción, y también se ha desarrollado un conjunto de investigaciones que, bajo el rótulo de derecho económico o estudios económicos del derecho, pretenden examinar la relación existente entre derecho y economía.

2 Se habló mucho de que ahora se debía abandonar el viejo concepto de las ventajas comparativas a la categoría novedosa de las nacientes ventajas competitivas.
No es nuestro papel juzgar si la racionalización legal formal por la que optaron los movimientos sociales al dar curso a sus litigios dentro de la administración de justicia fue una actitud ingenua o no, pero sí debemos subrayar que gran parte de los flujos de poder social en demanda de la materialización de los derechos formales se encontró y estrelló contra la pared de la congestión judicial. Como lo habíamos señalado más arriba, en el caso colombiano, el desarrollo inusitado en la profesionalización de la abogacía y el creciente número de universitarios egresados de las escuelas de derecho, la mayoría de ellas con una fuerte formación tradicional y dogmática, crearon las bases para este proceso de juridización de las relaciones sociales. Así las cosas, se puede advertir con Weber y muchos sociólogos jurídicos contemporáneos que el Estado de bienestar no solo tuvo como función la racionalización de las conductas sociales mediante el derecho, legal formal, sino que incluso llegó a generar excesos en ese proceso de racionalización que han permitido a esa "jaula de hierro" que es el derecho según Weber, socavar los principios racionales sobre los cuales se basa la libre empresa y de mercado, y ello debido a su tendencia a reducir a su más mínima expresión la ética del sujeto.

Sin embargo, en este proceso las profesiones cumplieron igualmente un papel muy importante $y$, en nuestro caso, fue muy significativo el desempeñado por los abogados técnico-jurídicos, porque a través del poder social que ellos desplazaron para poner en funcionamiento la máquina de la justicia ambas tendencias coincidieron para acelerar el atolladero de la congestión judicial.

Es necesario advertir también que a pesar de que Weber anticipó en todo este proceso un divorcio entre las lógicas del derecho racional material y el derecho racional formal, hoy en día se advierte una tendencia a que la decisión judicial se apoye cada vez más en el saber científico y técnico no solo operante en la empresa capitalista, sino en 
Ios más altos niveles de decisión de las diferentes instancias del Estado en su ejercicio de regulador o desregulador, a través de las políticas públicas. En este sentido, ambas racionalidades vuelven a vincularse mediante la apelación a una relación entre ciencia, técnica y eficiencia económica (propia del derecho racional material) y la racionalidad formal de los tribunales (técnica jurídica), dando lugar a un cierto abandono del concepto de burocracia que viene a ser sustituido por el concepto o categoría de tecnocracia. En este sentido, podemos decir que la tecnocracia internacional no produjo el mundo posterior al Estado de bienestar, sino que lo ha venido justificando y creando en él imaginarios, esperanzas o ilusiones frente a las turbulencias y contingencias del presente. En realidad, poco o nada interesa saber por qué se incumplen los contratos; lo que se ha introducido sutilmente en estos tiempos ha sido el papel "mágico" de los rituales del derecho en busca de solucionar las necesidades del mundo material. El escenario de los derechos que comienza a desprenderse desde este periodo parece sugerir que la vida es producida por el derecho o por una decisión judicial, y cada vez más se aleja de la memoria la época del acceso a la justicia.

\section{B. Transformaciones en los procesos de trabajo y su impacto en el derecho positivo}

\section{Características del derecho positivo del Estado benefactor}

Podemos señalar que las características básicas del derecho y la justicia dentro de la organización fordista del trabajo fueron las siguientes:

a. El Estado benefactor se caracterizó por lo que en teoría del derecho se denomina el "monismo jurídico" (ya analizado por Max Weber) que expresa la existencia de un solo sistema jurídico dentro del orden social. Tal fue el común denominador de la organización de las sociedades en los países occidentales.
La teoría kelseniana del derecho generó los lineamientos para la existencia del monismo jurídico (Wolkmer, 2006) bajo la égida del constitucionalismo o Estado constitucional de derecho, en donde el sistema legal debía estructurarse a partir de principios y normas de rango constitucional. A partir de la Constitución como norma de normas se establecía una serie de regulaciones legales, ceñidas todas a una estricta hermenéutica constitucional. Esto quiere decir que el contrato social contemplado en la constitución no podía ser organizado sino mediante los preceptos y la lógica constitucional. No era posible la existencia de ordenamientos legales no constitucionales y organizados por fuera de la estructura interpretativa de la norma superior. La racionalidad jurídica del sujeto de derecho, de su universalización, homogenización y autonomía, correspondía a los principios y valores del sistema legal que ordenaba todo el andamiaje constitucional.

b. De igual manera, se puede decir que el constitucionalismo kelseniano imponía necesariamente el centralismo legal. La interpretación jurídica debía adecuarse a los preceptos que estaban reservados al poder constitucional, el cual se encargaba del control de legalidad o de constitucionalidad de las normas jurídicas y de las decisiones judiciales. En consecuencia, no podían existir instancias distintas a la de un solo cuerpo central encargado de la custodia de la legalidad del orden normativo. La existencia de varias instituciones con cierto grado de autonomía en la interpretación jurisprudencial podía afectar el férreo control de la constitución sobre las demás actuaciones o disposiciones. En ese sentido, el constitucionalismo diseñado por Kelsen tenía un fuerte carácter centralista que permitía, a su turno, la conformación de una comunidad interpretativa y de sentido, más o menos permanente, en la custodia del orden constitucional y legal de la sociedad. A los jueces no les era permitido interpretar 
la ley, sino tan solo hacerla cumplir. Como se puede colegir, esta concepción es muy distinta de las posiciones que desde finales del siglo $\mathrm{XX}$ han defendido los académicos del nuevo constitucionalismo latinoamericano, inspirados parcialmente en el realismo norteamericano y en el subjetivismo de Dworkin.

c. En realidad, Kelsen no hizo otra cosa que desarrollar la forma de gobierno formulada por Montesquieu -caracterizada por la separación de poderes-, pero advirtiendo, a nuestro juicio, las dificultades que conllevarían una "politización de la administración de justicia". Él encuentra en el Estado constitucional de derecho una salida provisional a las posibles crisis internas del monismo jurídico, colocando a los jueces como subalternos de los otros órganos del poder de Estado y de la misma razón de este ultimo. La teoría pura del derecho no es más que la expresión de esta necesidad del poder de Estado; teoria que tuvo que transformarse en técnica del derecho.

d. De la misma forma se puede advertir que esta formación jurídica propia del Estado benefactor se caracterizó por el excesivo formalismo jurídico, especialmente de origen francés, en donde, principalmente por su carácter escrito, se le dio prevalencia a la formalidad de los procedimientos por encima de la justicia sustantiva. En otras palabras, en este periodo prevaleció la producción de la verdad jurídica. La verdad de los hechos se producía mediante los mecanismos formales de los procedimientos y primaba sobre la verdad real; la verdad procesal subordinaba a la verdad real. Una de las características más sobresalientes de la dogmática constitucional de este periodo fueron los mecanismos de interpretación constitucional, en donde la norma general pretendía abarcar todos los hechos sociales e incorporarlos a su armazón lógico-formal. La dogmática jurídica constreñía así la lógica de la producción de la verdad real a la lógica y racionalidad de la hermenéutica constitucional.

e. Sin duda una de las características más destacadas del sistema legal del Estado benefactor fue su interés en dar respuesta a la resolución individual de conflictos. En efecto, el sistema legal entendía que la lógica imperante en la sociedad civil y en la relación de esta con el Estado (derecho político) correspondía a relaciones entre individuos, con relativa excepción, por ejemplo, del derecho laboral e incluso del derecho agrario, dada su constitución con base en movimientos campesinos. La lógica del derecho civil, la de los contratos, etc. se reducía a una readecuación del conflicto social entre sujetos de derecho, que básicamente eran entendidos como personas naturales o jurídicas, y que entonces hacían aparecer los conflictos como conflictos individuales. Esta situación generaría, como lo veremos más adelante, parte de la crisis de este modelo, al aparecer dentro de la trama de la conflictividad social sujetos sociales colectivos que demandaban soluciones de la misma naturaleza y que el sistema legal no estaba en capacidad de resolver.

f. En cuanto a los mecanismos más idóneos de producción de la verdad jurídica, existían distintas formas de medios probatorios que se encontraban bajo la vigilancia y control del juez y para los cuales se le concedía a este la valoración de la prueba según los criterios de la sana crítica. Con el advenimiento de las transformaciones tecnológicas, y particularmente de la revolución técnico-científica, la situación del juez frente a los medios probatorios cambiaría. Podemos decir que la lógica instrumental de producción de la prueba se impuso sobre los criterios de valoración de la misma. La verdad técnico-científica penetró todo el proceso judicial y se impuso como verdad incontrovertible. Como nos lo advierte Habermas, la acción instrumental no requiere principios de discusión y 
subordina la acción comunicativa que prevalece en el seno mismo de esta. La ciencia y la técnica empezaron así a dominar y tener un valor destacado dentro de los procesos judiciales.

g. Por último, podemos destacar que la punición $y$ el castigo fueron las formas dominantes respecto al establecimiento de las penas. La cárcel, el hospital, la expropiación de bienes, la pérdida del empleo constituyen las formas más comunes de terminación de los conflictos sociales en este modelo, haciendo que la regulación de las relaciones sociales adquiera la forma de sociedad disciplinaria, en los términos y bajo el alcance sugerido por Michel Foucault.

\section{Principales cambios en el trabajo y en los derechos de la propiedad}

Durante la fase del bienestar ocurrieron fenómenos económicos sin precedentes no solo en relación con la racionalización de la sociedad por vía del derecho material y la estructuración y organización técnico-administrativa de la empresa capitalista con base en los desarrollos de los nuevos principios de la organización científica del trabajo; sino también en lo concerniente a la racionalización de la burocracia del Estado y, dentro de ella, a los cambios permanentes en el seno de la rama jurisdiccional. Podríamos enunciar, a manera de ejemplo, los más importantes efectos que produjo la racionalización del trabajo en el conjunto de la organización social productiva:

a) La fase de acumulación fordista se caracterizó por un aumento en el tamaño de la firma, debido no solo a la introducción de la naciente tecnología en serie, estandarizada y masificada, sino también a que su lógica o principio de organización racional se centró en las denominadas "economías de escala" que permitieron una reducción considerable de los costos fijos de las empresas. b) Como consecuencia de lo anterior, la empresa capitalista fordista entendió que la generación de lo que se conoce como "el efecto aglomeración" tuvo un impacto positivo dentro de su estructura de costos, al permitir, gracias a la cercanía o proximidad de la industria en su conjunto, reducir gastos como los de transporte, servicios generales, etc.

c) La industrialización fordista encontró igualmente útil construir un esqueleto industrial completo que le permitiera a los distintos sectores de la producción obtener la complementariedad industrial, hecho que motivó la introducción de la variable espacio-temporal dentro de la producción en general. De allí las teorías sobre la localización industrial de las firmas, la necesidad del mercado nacional y la homogenización del espacio de la producción, de suerte que pudiera lograrse una especie de universalización de la ley del valor-trabajo dentro del conjunto social.

Estas necesidades, que tuvieron como principio de racionalidad las nuevas condiciones de posibilidad del desarrollo técnico, fueron impulsadas y arrastradas en un movimiento incesante y hacia adelante por los ritmos de la competencia capitalista -monopolista o no-y por la acumulación ampliada del capital. En otras palabras, la organización fordista del trabajo, vista tan solo desde la perspectiva de la empresa, promovió un poderoso proceso de "socialización de las fuerzas productivas" a través de múltiples mecanismos, entre otros: la fusiones de empresas, los llamados cárteles que comparten mercado, la diversificación de productos y marcas pertenecientes a un solo grupo económico y la exacerbación de la división técnica y social del trabajo mediante el desplazamiento de los grupos económicos a sectores productivos distintos a los de sus tradicionales nichos productivos y de mercado. 
d) A pesar de que la feminización del mercado laboral durante ese periodo logró ampliar tendencialmente la oferta de mano de obra industrial necesaria para equiparar relativamente las necesidades de la demanda de trabajo para la industria con la perspectiva de llegar a la plena ocupación y el empleo que tanto buscaba Keynes, también es necesario advertir que se dio una mutación en la relación salarial con respecto a la del periodo anterior, pues el "salario familiar" del denominado obrero masa se convirtió en un salario individual o personal. Puede ser que el fondo general de salarios, incluido tanto el directo como el indirecto, haya aumentado, pero a costa de un mayor aporte de personas al servicio de la empresa capitalista y con consecuencias importantes para el conjunto de las relaciones sociales de producción, especialmente para la esfera de la reproducción social. Ahora bien, los desbalances permanentes del ciclo productivo de esta fase fueron imposibles de regular, particularmente debido a los excesos de productividad que no lograron encontrar una ecuación entre la oferta y la demanda de productos.

e) La sociedad se transformó para contrarrestar particularmente los problemas de liquidez de las empresas o para hacer frente a la necesidad de acelerar el ciclo de rotación del capital mediante dos mecanismos igualmente importantes, que posteriormente tendrían efectos perversos para el conjunto de la producción real y los sistemas de propiedad: de un lado, la empresa capitalista se transformó rápidamente en sociedad por acciones y, de otro, se especializó el sector bancario del sector productivo real, dando lugar a la autonomía relativa del capital financiero como capital especulativo. El resultado más visible fue la producción y el consumo al debe, esperando algún día pagar, mientras el capital financiero se alimentaba a pasos agigantados, todo bajo la falsa esperanza de poder saldar las cuentas y deudas adquiridas mediante un aumento de la producción. Los efectos al final de esta fase de acumulación se vieron prontamente: inflación galopante, imposibilidad de regulación de las tasas de interés, fuga de capitales, estanflación, etc. En síntesis, la regulación del modelo explotó o, en otras palabras, el modelo no tenía regulación sino en apariencia. La concentración y centralización del capital se exacerbó encunando en su seno la socialización de las fuerzas productivas por ella misma generadas.

\section{Determinantes de fondo de la crisis y derrumbe del derecho del Estado benefactor}

Con el agotamiento del modelo fordista de organización social, el derecho y la justicia que le fueron substanciales sufrieron un deterioro $y$ envejecimiento prematuro que hicieron necesario su replanteamiento. El derecho y la justicia de ese modo de organización social debieron ser superados, en la medida en que no lograban adecuarse a los nuevos requerimientos de la reestructuración de las relaciones sociales. Esta situación es realmente plausible pues, como lo advertimos más arriba, cada momento por el que ha transitado la organización social capitalista ha requerido la reorganización de las relaciones sociales $y$, dentro de ellas, de los principios de funcionamiento del derecho y los procesos de legitimación de la justicia, no solo para atender los requerimientos de las nuevas condiciones sociales, sino también para entronizar dentro del colectivo social nuevas normas y valores que posibiliten la aceptación e internalización de los derechos que surgen en toda la reorganización socio-política productiva, necesarios para la integración sistémica de las relaciones sociales.

A continuación quisiéramos presentar las concepciones más comunes que se han esgrimido para entender el decaimiento y reestructuración del derecho y la justicia del fordismo; concepciones que se han postulado como las determinaciones 
causales de la aparición de nuevas formas de regulación jurídica:

\section{a. Excesos en la centralización de la producción} del derecho y la justicia. Como anotábamos más arriba, el modelo kelseniano de derecho y justicia se caracterizó por ser altamente concentrado y centralista, lo que generó un cúmulo de demandas sociales alrededor del Estado que este fue incapaz de resolver. Se podría decir que la conflictividad social -incluyendo los conflictos de carácter regional- se centralizó en el Estado, dando lugar a un proceso de enfrentamiento irresoluble, en la medida en que el Estado no logró dar respuestas a las necesidades de solución de los conflictos, lo que ocasionó una aguda crisis de impunidad y de cogestión de la administración de justicia en cabeza de sus autoridades centrales.

Esta situación, a decir de muchos, hizo que se gestara una crisis de deslegitimación del Estado, el cual no lograba cumplir con una de sus principales funciones: producir justicia y, a través de ella, contener el conflicto social. La deslegitimación empezó a expresarse en el descrédito de los mecanismos formales de resolución de conflictos y en la necesidad de proveerse de formas diferentes a las convencionales para solucionar las controversias judiciales. A la par, el Estado empezó a ser percibido por gran parte de la población como un enemigo, pues al haber concentrado y centralizado en su seno numerosas funciones sociales, incrementadas en su papel de Estado providencia, aparecía como el primer y principal incumplidor del contrato social. Así, el Estado benefactor generó una crisis de legitimación de su propia racionalidad y, a su turno, impuso la necesidad de una reorganización de los mecanismos de producción social del derecho y la justicia.

b. Con esta situación, igualmente, se hizo visible un proceso de "politización" de la administración de justicia y del derecho respecto a las clases subalternas y, en adelante, los nuevos movimientos sociales encontraron en las negociaciones con los regímenes presidencialistas la única forma de hacer cumplir sus demandas y necesidades. Esto generó un fortalecimiento de la organización social o de la denominada sociedad civil, en tanto nuevo actor sociopolítico que enfrentó al Estado ya no en el terreno de la justicia y su imparcialidad, sino mediante su capacidad de construir e imponer en la negociación colectiva, cara a cara con este, temas que anteriormente se trataban en otras instancias.

Finalmente, podemos decir que no solo se deslegitimó la justicia en los términos de su "imparcialidad", sino que este hecho provocó ciertas tendencias al resquebrajamiento de las competencias y jurisdicciones del orden constitucional y legal, al mismo tiempo que el paulatino empoderamiento de las organizaciones sociales y la politización de la "sociedad civil" cuestionaban la capacidad de mando del Estado. La organización política administrativa del Estado tendió a pulverizarse al transformarse 0 construirse una nueva geografía de las luchas sociales y al cambiar las formas tradicionales de concebir el espacio regional o local en relación con los espacios nacionales e internacionales.

c. Cambios en la naturaleza del conflicto. Como es de conocimiento generalizado, el Estado benefactor generó la aparición de nuevos sujetos sociales, especialmente de carácter colectivo, al producir bienes de consumo colectivo y ampliar el proceso de socialización de cierta canasta de bienes. En ese proceso, la fuerzas productivas comenzaron a ser usadas mediante el ejercicio y práctica del trabajador colectivo, y se crearon los derechos sociales y económicos -o derechos de segunda generación-, permitiendo que una serie importante de bienes y servicios fueran derechos de importantes sectores de la población para efectos de su reproducción. 
Estos cambios que se operaron a través de las transformaciones de la relación salarial y, particularmente, de la instauración del denominado salario indirecto dieron lugar a una mutación de la naturaleza del conflicto social y de sus principales actores. Los movimientos sociales abanderaron reivindicaciones sociales de naturaleza colectiva, como los servicios públicos, la educación, la salud, la recreación, etc., ya no para satisfacer necesidades individuales sino como demandas de y para todos los ciudadanos. Estas reivindicaciones, sin embargo, no fueron atendidas, en parte porque el derecho $y$ la justicia del fordismo estaban diseñados para resolver controversias de naturaleza individual. Se podría decir que nació entonces un nuevo conflicto entre la satisfacción de las necesidades de carácter colectivo y las capacidades del Estado para resolver las demandas y reivindicaciones sociales de naturaleza individual.

Esta situación llevó a que el Estado exacerbara la crisis del derecho y la justicia, pues con la insuficiencia de sus respuestas no hizo más que suscitar un incremento en las necesidades de la producción de la justicia por parte de la población. Una forma temprana de percibir esta situación la encontramos en los trabajos del profesor José Eduardo Faria (1988, 1990, 1994). Podemos ampliar esta perspectiva diciendo que la denominada etapa de la congestión judicial estuvo íntimamente unida a la economía política de los servicios públicos, a las políticas de planificación urbana para América Latina entre 1970 y 1980 y, sin duda, a la crisis urbana propiciada por esta como resultado de los procesos de renovación urbana y la planificación inconclusa que la acompañó.

d. Crisis en las estructuras de la socialización. Es plausible señalar que el Estado benefactor organizó las relaciones entre clases sociales al permitir dentro del capitalismo industrial la coexistencia de las relaciones entre capital y trabajo. Mediante la legislación laboral construyó el sujeto clase, el cual, a su vez, permitió la existencia regulada y controlada de las clases sociales. Los primeros movimientos sociales fueron los pertenecientes al mundo agrario $y$ al mundo obrero.

Los sindicatos fueron las expresiones más tempranas de organización del trabajo dentro del Estado benefactor. Sin embargo, el precario equilibrio social rápidamente se rompió al aparecer en escena nuevas áreas de conflicto social con el surgimiento y desborde de los nuevos movimientos sociales en áreas diferentes a las que tradicionalmente habían sido reguladas por los sindicatos. Se puede apreciar cómo afloraron los movimientos urbanos de pobladores por el derecho a la ciudad, de actores sociales que reclamaban vivienda urbana denominados "grupos de viviendistas"; de mujeres, de ecologistas, de movimientos regionales, de negritudes, de indígenas, de movimientos sexuales, etc. En parte, la aparición de los nuevos movimientos sociales estuvo asociada a las promesas incumplidas por el Estado de bienestar, especialmente con la desatención incompleta del salario indirecto, y a las luchas por la autonomía de estos movimientos frente al Estado en la búsqueda de nuevas formas de producción del poder y la política.

En ese sentido, podemos advertir que durante este periodo hubo un proceso de exacerbación de las luchas sociales en todos los órdenes, denotando una crisis de socialización de las instituciones encargadas de mantener la cohesión social. Esta crisis, caracterizada por la desintegración social, la pérdida de los elementos estructurantes de la cohesión social y la desestructuración del proyecto utópico del Estado de bienestar, generó una ampliación del horizonte de sentido de los movimientos sociales en el que se hizo evidente un resquebrajamiento del sujeto social y la aparición de 
nuevas estructuras de producción de normas, valores e imágenes del mundo que no se adecuaban a las constituidas dentro del paradigma del mundo industrial.

La crisis de socialización estuvo ligada a la aparición de nuevos proyectos sociales que el Estado benefactor no estaba preparado para integrar en su seno. En consecuencia, podemos advertir una crisis del derecho de este periodo asociada a la crisis de socialización anteriormente mencionada. La crisis de la justicia se expresó de varias formas pero particularmente en la existencia de procedimientos judiciales largos y engorrosos frente a necesidades que requerían soluciones relativamente expeditas; a la vez, la exacerbación de los conflictos creó una cogestión en los despachos judiciales que terminó por aumentar la insatisfacción de la población en lo concerniente a la producción de la justicia y por agravar la impunidad, con los resultados que esto conlleva. De la misma forma, empezó a gestarse la organización y sindicalización de la rama judicial, que condujo, entre otras consecuencias, a una ruptura con la interpretación jurisprudencial.

e. Se ha señalado también que la autonomía de las ramas del poder público y su equilibrio se vieron rotos a causa de la politización de la justicia, en la medida en que el poder judicial se vio penetrado por el ejecutivo en sus decisiones, lo que provocó una visión crítica frente a la justicia según la cual ya no se decidía en derecho, y la política y las relaciones de poder prevalecían en la decisión judicial.

f. Podemos advertir cómo el fenómeno mundial de la corrupción se tomó el aparato jurisdiccional conduciendo a la compra y degradación de la justicia, particularmente con la presencia del "capital mafioso o criminal", que se introdujo en ella para obtener las decisiones judiciales más convenientes, desnaturalizando plenamente el Estado de derecho. g. Otra explicación igualmente importante de la crisis del derecho fordista ha sido la de constatar el resquebrajamiento del monismo jurídico ocasionado por la aparición del pluralismo del derecho, entendido como la coexistencia de varios órdenes jurídicos dentro de un mismo espacio social y territorial. La justicia indígena es tan solo una de las expresiones de este fenómeno. Nuevos y variados sujetos sociales se vienen visibilizando desde hace algún tiempo, y su empoderamiento ha devenido en la instauración de formas de regulación jurídica y de producción de justicia que se desarrollan por fuera de los canales regulares del Estado. Es el caso de la justicia alternativa o emergente, que pretende construir identidades capaces de dotarse ellas mismas de mecanismos para la resolución de conflictos. Es una forma de reconstruir el poder social de las comunidades por fuera del Estado a partir del reconocimiento de un sí mismo, de un sujeto que se reconoce en su propia identidad.

En parte, este fenómeno del pluralismo jurídico implica un espacio de robustecimiento de la sociedad civil que busca adquirir cierta organicidad política, generando a la vez un proceso de despolitización del Estado y de politización de la sociedad civil. Sin embargo, en nuestro medio aún queda por hacer un análisis más detallado de esta temática, en especial sobre su significación política, en la medida en que debe precisarse mejor el alcance del pluralismo jurídico, la pluralidad de derechos y los derechos plurales; todos ellos pueden apuntar a comprensiones totalmente diferentes del modo de entender y encarar el mundo de la multiculturalidad y la interculturalidad, sus potencialidades y limitaciones.

h. Existe una característica no suficientemente reseñada en todo este proceso y que se encuentra íntimamente relacionada con la lógica del conflicto, particularmente en Colombia. 
Podemos señalar que las pretensiones del positivismo jurídico de construir un ordenamiento legal general y único, que incluyera todas las conductas posibles mediante su tipología y normativización, y que incluso dispusiera de herramientas prácticas para dirigir la hermenéutica del derecho, se han mostrado rígidas y obsoletas. Mientras que, siguiendo este modelo, se apelaba a los principios generales del derecho y a sus fuentes formales y materiales, el dinamismo y variedad de la vida urbana hicieron emerger nuevos conflictos y, con ellos, una enorme "multiplicidad" de temas, áreas y problemas del litigio y de las controversias sobre la propiedad, de tal forma que el Estado fue impulsado reiteradamente a generar una abundante legislación para regular los "casos concretos". Sin duda alguna, esta situación dio lugar al fenómeno de la "hiperinflación normativa" que ha producido impactos negativos sobre la estructura del monismo jurídico.

i. Asistimos a la pérdida de sistematización y coherencia del ordenamiento legal que defendía Kelsen, lo cual dificulta la tarea técnica de la aplicación de la ley; en segundo lugar, se ha dado un proceso acelerado de "descodificación" del derecho, en la medida en que la legislación de "coyuntura" ha venido sustituyendo la lógica y racionalidad que de cierta manera se encontraba presente en los códigos; en tercer lugar, la amplia proliferación normativa viene propiciando el desarrollo y exacerbación del conocimiento especializado de los abogados, lo que, en términos de las instituciones -públicas o privadas-, ha generado un grado de dificultad muy alto para una comprensión aceptable del manejo de "sus negocios" y la forma de la administración de estos. Finalmente, esta situación en que se ven comprometidas las instituciones y los individuos sin duda alguna rompió el sacro principio de la "seguridad jurídica" defendido por el positivismo jurídico, debido a las dificul- tades asociadas a la comprensión razonable de la descodificación y el permanente cambio normativo y envejecimiento de la regulación jurídica.

j. Por último, la crisis de legitimación del Estado, la aparición de formas autónomas de poder social, especialmente en el seno de la sociedad civil, la presencia y constitución de nuevas formas de las relaciones sociales, la aparición de nuevas y paralelas estructuras económicas como es el caso de la economía informal o popular, la existencia de un ejército de trabajadores no articulado a la economía moderna, etc. están produciendo una crisis de integración sistémica dentro del capitalismo contemporáneo. Esta situación viene acompañada de la aparición de nuevas formas de regulación social, dentro de ellas las del derecho, permitiendo a su turno que en la sociedad del Estado benefactor se produzcan altos índices de desintegración y desarticulación del tejido social. En este sentido podemos advertir cómo la crisis del Estado es a la vez una crisis del derecho.

\section{CONCLUSIONES}

Podemos señalar que en este artículo hemos afirmado que para comienzos del siglo XXI el modelo positivista kelseniano que caracterizó el ordenamiento jurídico colombiano evidencia un verdadero agotamiento que presagia la naturaleza de su propia crisis. Sin duda han sido múltiples los factores que han contribuido a su deterioro y que en este artículo hemos sucintamente presentado.

Sin embargo, podríamos decir que la naturaleza de la crisis de dicho modelo de ordenamiento legal está íntimamente relacionada por dos variables de suma importancia: de un lado, los determinantes asociados con la dinámica y forma de expresión del conflicto social en Colombia, es decir, con la dinámica de los movimientos sociales $y$, de otro lado, pensamos que las transformaciones de los procesos de trabajo que vienen operando y trans- 
formando la dinámica del capitalismo colombiano han impactado profundamente el modelo jurídico propio del periodo del Estado de bienestar. Especialmente con los procesos de desterritorialización de la producción, la introducción de la revolución tecnológica de la telemática y la biotecnología se vienen transformando aceleradamente las relaciones sociales de producción de la sociedad colombiana.

Abandonamos cada vez más la imagen del obreromasa y nos adentramos en una fase en donde se desarrolla el predominio tendencial del trabajo intelectual, en donde se desintegran las antiguas formas de medición y control del trabajo y finalmente se expulsa del ordenamiento legal la idea o hegemonía del sujeto de derecho, particularmente en la forma de su universalización, generalidad y abstracción. Renace con fuerza el fenómeno de la emancipación de nuevas subjetividades, la aparición del fenómeno de la multiculturalidad como el surgimiento de nuevos principios de legitimación jurídica basados o más próximos a las tesis iusnaturalistas. La legitimación del nuevo derecho que irrumpe dentro de la sociedad colombiana pretende construir principios de legitimación jurídica y social basados en principios provenientes del conocimiento científico-técnico y de la revolución tecnológica en curso.

\section{REFERENCIAS}

Bobbio, N. (1998). El positivismo jurídico. Madrid: Debate.

Bourdieu, P. (2001). Poder, derecho y clases sociales. Bilbao: Desclée De Brouwer.

Carrillo, Y. (2009). La inclusión de la moral en el derecho y la encrucijada actual del positivismo jurídico. Revista Diálogo de Saberes, 31, 213-231.
Carvajal, J. (2009). El aporte de las instituciones no gubernamentales a la sociología jurídica en CoIombia". Revista Diálogo de Saberes, 31, 189-200.

Díaz, E. (1981). Sociología y Filosofía del Derecho Madrid: Taurus.

Durkheim, E. (1992a). De la división del trabajo social: estudio sobre la organización de las sociedades superiores. Madrid: Akal editor.

Durkheim, E. (1992b). Las formas elementales de la vida religiosa. Madrid: Akal editor.

Edelman, B. (1978). Elementos para una teoría marxista del derecho. Medellín: Editorial 8 de junio.

Faria, J.E. (1988). Direito e justiça. A função social do judiciário. São Paulo: Ática.

Faria, J.E. (1990). El poder judicial ante los problemas colectivos. El otro derecho - ILSA, 5.

Faria, J.E. (org.). (1994). Direitos humanos, direitos sociais e justiça. São Paulo: Malheiros Editores.

García, M. (2001). Sociología jurídica. Teoría y sociología del derecho en Estados Unidos. Bogotá: Unibiblos.

Marx, C. (1980). Crítica del derecho del Estado hegeliano. Caracas: Ed. Universidad Central de venezuela.

Moncayo, V. (1990). Sobre la naturaleza del derecho como forma social de la dominación. Revista Jurisprudencias - ILSA, 1, 11-24.

Negri, T. y Hardt, M. (2001). Imperio. Bogotá: Ediciones desde abajo.

Negri, T. (2008). La fábrica de porcelana. Una nueva gramática de la multitud. Barcelona: Paidós.

Pashukanis, E. (1976). Teoría general del derecho y el marxismo. Medellín: La Pulga. 
Pérez Perdomo, R. (2004). Los abogados de América Latina. Bogotá: Universidad Externado de Colombia.

Polanyi, K. (1997). La gran transformación. Crítica del liberalismo económico. Madrid: Ediciones de la Piqueta.

Rodríguez, E. (2006). La producción de la subjetividad en Durkheim, Marx y Habermas. En J. Estrada. (Ed.). Teoría y acción política en el capitalismo actual (133-166). Bogotá: Universidad Nacional de Colombia.

Rodríguez, E. (2008). Derecho, ciudad y sociedad. Colección Estudios Socio-Jurídicos No. 3. Bogotá: Centro de investigaciones socio jurídicas. Universidad Innca de Colombia.
Rubin, I. (1979). Ensayo sobre la teoría marxista del valor. Cuadernos de pasado y presente. México: Siglo XXI.

Schmidt, A. (1982). El concepto de naturaleza en Marx, Bogotá: Siglo XXI.

Sohn Rethel, A. (1979). Trabajo intelectual, trabajo manual. Bogotá: Viejo Topo.

Treves, R. (1985). Introducción a la sociología del derecho. Madrid: Taurus.

Wolkmer, A. (2006). Introducción al pensamiento jurídico crítico. México: ILSA-Universidad Autónoma de San Luis de Potosí. 